\title{
Multi-element analyses of earthworms for radioecology and ecotoxicology
}

\author{
S. Yoshida ${ }^{1}$, Y. Muramatsu ${ }^{2}$ and W.J .G.M. Peijnenburg ${ }^{3}$ \\ ${ }^{1}$ Environmental and Toxicological Sciences Research Group, National Institute of \\ Radiological Sciences, Anagawa 4-9-1, Inage-ku, Chiba-shi, Chiba 263-8555, Japan \\ ${ }^{2}$ Department of Chemistry, Faculty of Science, Gakushuin University, Mejiro 1-5-1, \\ Toshima-ku, Tokyo 171-8588, Japan \\ ${ }^{3}$ Laboratory for Ecotoxicology, National Institute of Public Health and Environmental \\ Protection, PO Box 1, 3720 BA Bilthoven, The Netherlands
}

\begin{abstract}
Earthworms and their growth media were analyzed for 33 elements, including radionuclide related elements such as $\mathrm{Cs}$, $\mathrm{Sr}$ and $\mathrm{U}$, in order to obtain basic information on the transfer parameters of the elements. The earthworms analyzed were Eisenia foetida fed in the laboratory by using cotton linters or leaf litter. The concentrations and transfer factors (TFs) of the elements were determined. Relatively high TFs were observed for $\mathrm{Na}, \mathrm{Mg}, \mathrm{P}, \mathrm{K}, \mathrm{Ca}, \mathrm{Co}, \mathrm{Ni}, \mathrm{Cu}, \mathrm{Zn}, \mathrm{Rb}$, Mo and Cd. The TFs for Al, Sc, Ti, Y, Nb and lanthanide elements were low. The TFs of alkaline elements, $\mathrm{K}, \mathrm{Rb}$ and $\mathrm{Cs}$, decrease with atomic number. The TFs of Cs were 0.16 for both media. Multi-element analyses could provide much information on the concentration and transfer of elements for earthworms which are one candidate reference organism for environmental radiation protection studies.
\end{abstract}

\section{INTRODUCTION}

Increasing concern about environmental radiation protection has raised awareness that more information is required on the transfer and accumulation of radionuclides in the biological compartments of ecosystems. The International Commission on Radiological Protection (ICRP) is planning to select worm as one of the reference organisms in their radiation protection recommendations. Earthworms play an important role in ecosystems, and might be a good indicator of soil contamination and its effect on the ecosystem. The Organization for Economic and Cooperative Development (OECD) has recommended the use of earthworm mortality for the chemical toxicity test [1]. Several biomarkers such as DNA alterations and Cholinesterase activity in earthworms following exposure to chemicals were also proposed [2]. The elemental composition of earthworms gives useful information on background levels and possible accumulation of toxic metals as well as related radionuclides. In addition, a change of the elemental composition itself might be a possible indicator of effects on earthworms and/or ecosystems. However, data for the elemental composition of earthworms are limited except for some specific heavy metals such as $\mathrm{Cd}, \mathrm{Zn}, \mathrm{Pb}$ and $\mathrm{Cu}$ [e.g. 3-5]. Data on multi-element concentration in earthworms were reported by Zheng et al. [6] and Rossbach and Stoeppler [7]. There are, however, no reports for multi-element transfer from a medium to earthworms. Although accumulation of radiocesium was studied by several scientists as summarized by Brown and Bell [8], the accumulations of other radionuclides have been reported in only a limited number of references.

The objective of this work is to provide basic information needed for an earthworm feeding method, a multi-element analysis method, and elemental composition and transfer parameters of the elements for the earthworm. Both the earthworms fed in the laboratory and their growth media were 
analyzed for more than 30 elements, including radionuclide related elements such as $\mathrm{Cs}$, $\mathrm{Sr}$, and $\mathrm{U}$, by using inductively coupled plasma mass spectrometry (ICP-MS) and inductively coupled plasma atomic emission spectrometry (ICP-AES).

\section{MATERIALS AND METHOD}

Earthworms grown in a laboratory were subjected to analyses. Thirty earthworms (Eisenia foetida) were fed upon leaf litter or cotton linters for 20 days at $20{ }^{\circ} \mathrm{C}$. The leaf litter used was partially fermented leaves commercially sold for gardening. The cotton linters were obtained as a by-product during cotton

Table 1. Concentrations of 33 elements analyzed for earthworms and their growth media, cotton linters and leaf litter ( $\mu \mathrm{g} / \mathrm{g}$-dry).

\begin{tabular}{|c|c|c|c|c|c|c|c|c|c|c|}
\hline \multirow[b]{2}{*}{$\mathrm{Na}$} & \multicolumn{2}{|c|}{$\begin{array}{l}\text { E. foetida } \\
\text { (Cotton) }\end{array}$} & \multicolumn{3}{|c|}{$\begin{array}{c}\text { E. foetida } \\
\text { (Litter) }\end{array}$} & \multicolumn{2}{|c|}{ Cotton linters } & \multicolumn{3}{|c|}{ Leaf litter } \\
\hline & 6200 & \pm 490 & 8500 & \pm & 330 & 1880 & \pm 89 & 1780 & \pm 1 & 140 \\
\hline Mg & 1270 & \pm 72 & 1280 & \pm & 21 & 519 & \pm 18 & 5540 & \pm 9 & 92 \\
\hline $\mathrm{Al}$ & 29 & \pm 0.23 & 21 & \pm & 2.4 & 3250 & \pm 400 & 4760 & \pm 3 & 366 \\
\hline $\mathrm{P}$ & 10500 & \pm 280 & 10100 & \pm & 300 & 383 & \pm 6 & 8130 & \pm 1 & 190 \\
\hline $\mathrm{K}$ & 11200 & \pm 340 & 9200 & \pm & 360 & 829 & \pm 180 & 10600 & \pm 5 & 57 \\
\hline $\mathrm{Ca}$ & 3170 & \pm 270 & 4060 & \pm & 140 & 1690 & \pm 61 & 40500 & \pm 2 & 2800 \\
\hline Sc & 0.014 & \pm 0.001 & 0.009 & \pm & 0.001 & 0.36 & \pm 0.07 & 1.00 & \pm 0 & 0.07 \\
\hline $\mathrm{Ti}$ & 1.14 & \pm 0.004 & 1.07 & \pm & 0.37 & 86.3 & \pm 14 & 343 & \pm 4 & 48 \\
\hline $\mathrm{V}$ & 0.57 & \pm 0.24 & 0.35 & \pm & 0.03 & 1.18 & \pm 0.21 & 7.73 & \pm 0 & 0.60 \\
\hline $\mathrm{Cr}$ & 3.02 & \pm 0.11 & 1.22 & \pm & 0.06 & 4.14 & \pm 0.49 & 11.7 & \pm 0 & 0.78 \\
\hline $\mathrm{Mn}$ & 12.8 & \pm 0.61 & 8.99 & \pm & 0.40 & 17.7 & \pm 1.3 & 1350 & \pm 3 & 33 \\
\hline $\mathrm{Fe}$ & 302 & \pm 33 & 324 & \pm & 13 & 649 & \pm 120 & 3180 & \pm 2 & 230 \\
\hline Co & 1.49 & \pm 0.16 & 1.82 & \pm & 0.09 & 0.17 & \pm 0.0002 & 1.67 & \pm 0 & 0.06 \\
\hline $\mathrm{Ni}$ & 2.63 & \pm 0.14 & 1.51 & \pm & 0.04 & 1.98 & \pm 0.20 & 10.5 & \pm 0 & 0.04 \\
\hline $\mathrm{Cu}$ & 12.3 & \pm 1.7 & 10.6 & \pm & 0.66 & 3.68 & \pm 0.20 & 20.7 & \pm 0 & 0.11 \\
\hline $\mathrm{Zn}$ & 136 & \pm 0.9 & 139 & \pm & 14 & 31.0 & \pm 5.6 & 156 & \pm 1 & 1.3 \\
\hline $\mathrm{Rb}$ & 11.0 & \pm 0.18 & 8.01 & \pm & 0.21 & 3.23 & \pm 0.64 & 19.6 & \pm 0 & 0.11 \\
\hline $\mathrm{Sr}$ & 14.4 & \pm 1.5 & 5.01 & & 0.29 & 17.0 & \pm 1.2 & 95.0 & \pm 3 & 3.9 \\
\hline $\mathrm{Y}$ & 0.033 & \pm 0.003 & 0.008 & \pm & 0.002 & 1.24 & \pm 0.11 & 2.76 & \pm 0 & 0.18 \\
\hline $\mathrm{Nb}$ & 0.004 & \pm 0.0004 & 0.003 & \pm & 0.0009 & 0.17 & \pm 0.01 & 1.01 & \pm 0 & 0.13 \\
\hline Mo & 0.76 & \pm 0.05 & 0.82 & & 0.03 & 0.17 & \pm 0.01 & 1.43 & \pm 0 & 0.06 \\
\hline $\mathrm{Cd}$ & 1.08 & \pm 0.16 & 1.32 & \pm & 0.10 & 0.040 & \pm 0.002 & 0.58 & \pm 0 & 0.004 \\
\hline Sn & 0.069 & \pm 0.0003 & 0.046 & \pm & 0.004 & 0.21 & \pm 0.02 & 0.48 & \pm 0 & 0.04 \\
\hline $\mathrm{Sb}$ & 0.016 & \pm 0.001 & 0.014 & & 0.000 & 0.12 & \pm 0.01 & 0.40 & \pm 0 & 0.03 \\
\hline Cs & 0.27 & \pm 0.003 & 0.094 & \pm & 0.003 & 1.72 & \pm 0.25 & 0.59 & \pm 0 & 0.03 \\
\hline $\mathrm{Ba}$ & 2.25 & \pm 0.22 & 0.53 & \pm & 0.07 & 18.0 & \pm 2.3 & 131 & \pm 4 & 4.2 \\
\hline $\mathrm{La}$ & 0.025 & \pm 0.002 & 0.01 & \pm & 0.002 & 1.08 & \pm 0.10 & 4.04 & \pm 0 & 0.27 \\
\hline $\mathrm{Ce}$ & 0.046 & \pm 0.004 & 0.015 & \pm & 0.004 & 2.24 & \pm 0.23 & 6.97 & \pm 0 & 0.41 \\
\hline $\mathrm{Sm}$ & 0.007 & \pm 0.0005 & 0.0013 & \pm & 0.0001 & 0.23 & \pm 0.02 & 0.68 & \pm 0 & 0.04 \\
\hline $\mathrm{Eu}$ & 0.002 & \pm 0.0003 & 0.0007 & \pm & 0.0001 & 0.052 & \pm 0.004 & 0.15 & \pm 0 & 0.01 \\
\hline $\mathrm{Gd}$ & 0.007 & \pm 0.0008 & 0.0018 & \pm & 0.0002 & 0.22 & \pm 0.02 & 0.60 & \pm 0 & 0.03 \\
\hline $\mathrm{Pb}$ & 0.46 & \pm 0.04 & 0.19 & \pm & 0.001 & 1.23 & \pm 0.001 & 14.2 & \pm 0 & 0.24 \\
\hline $\mathrm{U}$ & 0.029 & \pm 0.003 & 0.013 & \pm & 0.00003 & 0.081 & \pm 0.01 & 0.25 & \pm 0 & 0.0002 \\
\hline
\end{tabular}


yarn production. No elements were added artificially. After 20 days, the body surfaces of the worms were rinsed with de-ionized water to remove all media particles. Then, they were kept in de-ionized water for 3 days at $12{ }^{\circ} \mathrm{C}$ to remove the materials inside their guts, before they were freeze dried, and pulverized. The leaf litter and cotton linters were also analyzed after being dried and powdered.

Each sample $(0.2 \mathrm{~g})$ was digested in a Teflon ${ }^{\mathrm{TM}}$ PFA pressure decomposition vessel with acids $\left(\mathrm{HNO}_{3}, \mathrm{HF}\right.$ and $\left.\mathrm{HClO}_{4}\right)$. A microwave digester (CEM Mars 5) was used to heat the samples for 1 to $2 \mathrm{~h}$. After digestion, the samples were evaporated to dryness. Then, the residues were dissolved in $2 \% \mathrm{HNO}_{3}$ to yield the sample solutions.

Trace elements were measured by ICP-MS (Agilent Technologies Inc. 7500). Rhodium and Bi were used for internal standards to compensate for changes in analytical signals during the operation. Major elements such as $\mathrm{Na}, \mathrm{K}, \mathrm{Mg}, \mathrm{Ca}$ and $\mathrm{P}$ were analyzed by ICP-AES (Seiko Instruments Inc. VISTA-PRO). Standard solutions were prepared from SPEX Multi-Element Plasma Standards (SPEX Industries Inc.) and used to get calibration curves. Several standard reference materials were used to validate the analytical procedure. Details for the analyses have been described by Yoshida and Muramatsu [9]. Totally 33 elements were determined by ICP-MS and ICP-AES.

\section{RESULTS AND DISCUSSION}

Analytical results of earthworms as well as their growth media, cotton linters and leaf litter, are shown in Table 1. The earthworms, although fed two different media, had similar elemental compositions to each other, especially for major elements, Na, Mg, P, K and Ca. The highest concentration ( $\mu$ g/g-dry) in earthworms fed cotton linters was found for K (11200) followed by P (10500), Na (6200), Ca (3170) and $\mathrm{Mg}$ (1270). For earthworms fed in leaf litter, the highest value was found for P (10100) followed by K (9200), $\mathrm{Na}$ (8500), Ca (4060) and Mg (1280). The elemental compositions of media for those major elements differed between cotton linters and leaf litter. Concentrations of P, K, Ca and $\mathrm{Mg}$ in leaf litter were more than ten times higher than those in cotton linters. These observations seemed to indicate that the concentrations of the major essential elements might be controlled biologically and were kept at constant values.

In order to estimate the accumulation of each element by earthworms, transfer factors (TFs) from media to earthworms were calculated. TF was defined as the ratio of "concentration in earthworm on dry weight basis" to "concentration in medium on dry weight basis". The calculated TFs

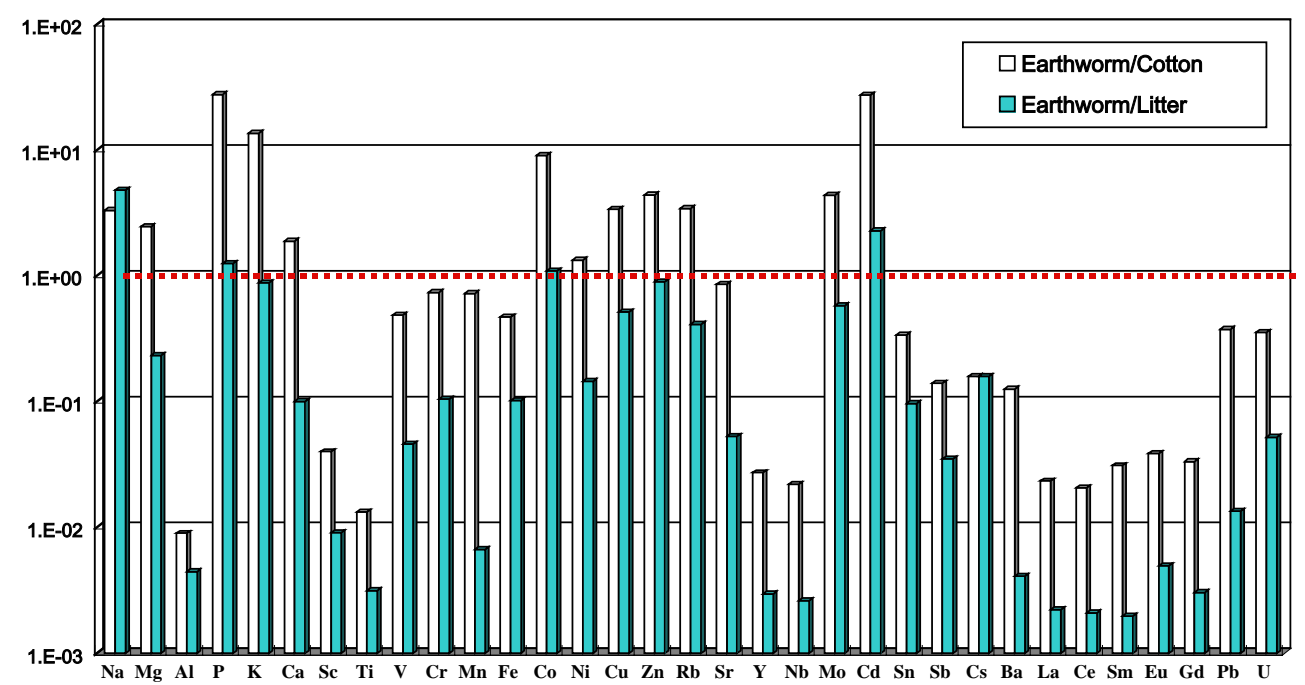

Figure 1. Transfer factors (TFs) for earthworms from two different media, cotton linters and leaf litter, for 33 elements analyzed. 
for 33 elements are summarized in Fig. 1. The TFs ranged widely depending on the elements. The patterns of the TFs were similar between the earthworms fed upon cotton linters and those fed upon leaf litter, although the value for each element was higher in the former for almost all elements. Relatively high TFs were observed for $\mathrm{Na}, \mathrm{Mg}, \mathrm{P}, \mathrm{K}, \mathrm{Ca}, \mathrm{Co}, \mathrm{Ni}, \mathrm{Cu}, \mathrm{Zn}, \mathrm{Rb}, \mathrm{Mo}$ and $\mathrm{Cd}$. There are several reports on $\mathrm{Cd}, \mathrm{Zn}, \mathrm{Pb}$ and $\mathrm{Cu}$ in earthworms regarding concentration, transfer, chemical form and controlling factors [e.g. 3-5]. The TFs greater than unity have been found for $\mathrm{Cd}, \mathrm{Pb}$ and/or $\mathrm{Zn}$ in many studies [e.g. 10-12]. Accumulations of $\mathrm{Pb}$ and $\mathrm{Cd}$ in the gut wall were observed [13] and Cd-metallothionein was isolated from earthworm [14]. The relatively low TF of Pb observed in the present work might be attributable to the low bio-availability of $\mathrm{Pb}$ in the media. High TFs of $\mathrm{Co}, \mathrm{Ni}, \mathrm{Rb}$ and Mo were not reported in any previous studies.

The TFs for Al, Sc, Ti, Y, Nb and lanthanide elements were low. Since elements such as Al, Sc and Ti are typically found in soil minerals, the low TFs observed here indicate the complete removal of soil minerals from the inside of the guts before the analyses. It is interesting to note that TFs of $U$ were higher than those of lanthanide elements in both media. In the soil-plant system, the TFs of $U$ and lanthanide elements do not differ with each other [9]. Sheppard and Evenden [15] demonstrated that the uptake of $U$ from soil to earthworms depended on the bio-availabilities of $U$ in the soils. Uptake mechanisms of $U$ by earthworms should be studied further.

The TFs of alkaline elements, $\mathrm{K}, \mathrm{Rb}$ and $\mathrm{Cs}$, decreased with atomic number. The TFs of Cs were 0.16 both for the earthworms fed cotton linters and the earthworms fed leaf litter. Retention of radiocesium by earthworms feeding upon leaf litter or soil is described as a two-compartment retention system, consisting of non-assimilated and assimilated radiocesium [8, 16]. Non-assimilated radiocesium can be eliminated with the gut contents with relatively rapid half-life (0.2 - 0.6 days). The TFs for earthworms cleared of their gut contents were reported to range from 0.03 to 0.06 [8]. Those values were similar to those observed in the present work for stable Cs. The TFs of radiocesium calculated on the basis of equilibrium concentration with the liquid media were much higher, and ranged from 7.3 to 37.9 [17].

The TFs of alkaline earth elements and Mg also decreased with atomic number. The TFs of Sr were 0.85 for the earthworm fed upon cotton linters and 0.05 for the earthworm fed upon leaf litter.

The higher TFs observed in earthworms fed upon cotton linters than those in earthworms fed upon leaf litter might be attributable to the higher bio-availabilities of the elements in the cotton linters. Further investigations are required for the bio-availabilities of the elements in the media.

Multi-element analyses have provided much information on the concentration and transfer of elements for earthworms. Such studies could be useful in collecting basic information on the reference organisms for environmental radiation protection. We are currently studying samples collected in a natural environment in the Netherlands. This new study is expected to yield comprehensive information on the concentration and transfer of multi-elements in earthworms and soil systems.

\section{Acknowledgements}

We wish to express our thanks to Mr. S. Yamazaki (Tokyo Nuclear Co.) and Ms. K. Kikuchi for their technical assistance.

\section{References}

[1] OECD, "Earthworm, acute toxicity tests”, OECD guideline for testing of chemicals 207 (1984).

[2] Scott-Fordsmand J.J. and Weeks J.M., "Review of selected biomarkers in earthworms", Advances in earthworm ecotoxicology, Sheppared S. et al. Eds., SETAC Press, FL USA, 1998, pp. 173-189.

[3] Morgan J.E. and Morgan A.J., Environ. Pollut. 54 (1988) 123-128.

[4] Peijnenburg W.J.G.M., Baerselman R., de Groot A.C., Jager T. Posthuma L. and Van Veen R.P.M., Ecotoxicol. Environ. Safety 44 (1999) 294-310. 
[5] Heikens A., Peijnenburg W.J.G.M. and Hendriks A.J., Environ. Pollut. 113 (2001) 385-393.

[6] Zheng J., Goessler W., Geiszinger A., Kosmus W., Chen B., Zhuang G., Xu K. and Sui G., J. Radioanal. Nucl. Chem. 223 (1997) 149-155.

[7] Rossbach M. and Stoeppler M., Fresenius Z. Anal. Chem. 332 (1988) 636-639.

[8] Brown S.L. and Bell J.N.B., Environ. Pollut. 88 (1995) 27-39.

[9] Yoshida S. and Muramatsu Y., Intern. J. Environ. Anal. Chem. 67 (1997) 49-58.

[10] Martin M.H. and Coughtrey P., Chemosphere 5 (1976) 313-318.

[11] Ma W., Edelman T., van Beersum I. and Jans T., Bull. Environ. Contam. Toxicol. 30 (1983) 424-427.

[12] Carter A., Can. J. Zool. 61 (1983) 2751-2757.

[13] Andersen C. and Laursen J., Pedobiologia 24 (1982) 347-356.

[14] Suzuki K.T., Yamamura M. and Mori T., Arch. Environ. Contam. Toxicol. 9 (1980) 415-424.

[15] Sheppard S.C. and Evenden W.G., Arch. Environ. Contam. Toxicol. 23 (1992) 117-124.

[16] Crossley D.A. Jr., Reichle D. E. and Edwards C.A., Pedobiologia, Bd. 11 S. (1971) 71-76.

[17] Janssen M.P.M., Glastra P. and Lembrechts J. F. M. N., Environ. Toxicol. Chem. 15 (1996) 873-877. 